\title{
Vozes de paixão em Cantares de perda $e$ predileção, de Hilda Hilst ${ }^{*}$
}

\author{
Luís Alberto dos Santos Paz Filho (PUCRS)** \\ https://orcid.org/0000-0003-4667-8186
}

\section{Resumo:}

0 presente trabalho tem como objetivo realizar uma interpretação da obra Cantares de perda e predileção, de Hilda Hilst, de forma a estabelecer relações entre poema e canção como método e metáfora para as concepções de paixão apresentadas em seus poemas. Para a realização desta leitura, conta-se como guia os estudos de Emil Staiger, Thomas Stearns Elliot e Octavio Paz acerca da poesia lírica, no tocante à musicalidade e voz poética, pretendendo constituir uma hipótese interpretativa da paixão em quatro poemas selecionados na obra da autora.

Palavras-chave: Hilda Hilst; paixão; canção; poesia.

\section{Abstract: \\ Voices of passion in Cantares de perda e predileção, by Hilda Hilst}

The present work aims to perform an interpretation of Cantares de perda e predileção, by Hilda Hilst, in order to establish relationships between poem and song as a method and metaphor for the conceptions of passion presented in her poems. In order to carry out this reading, the studies of Emil Staiger, Thomas Stearns Elliot and Octavio Paz about lyric poetry, with regard to musicality and poetic voice, are counted as a guide, intending to constitute an interpretive hypothesis of passion in four poems selected in the work of author.

Keywords: Hilda Hilst; passion; song; poetry.

Agência de fomento: "O presente trabalho foi realizado com apoio da Coordenação de Aperfeiçoamento de Pessoal de Nível Superior - Brasil (CAPES) - Código de Financiamento 001.

** Mestre em Letras/Teoria da Literatura / Doutorando em Teoria da Literatura. Programa de Pós-Graduação em Letras da Pontifícia Universidade Católica do Rio Grande do Sul. Lattes: http://lattes.cnpq. br/2848683122794062.E-mail: Luis.paz@edu.pucrs.br 


\section{Um eu que sempre canta: a questão da voz e suas razões musicais na poesia lírica}

0 mundo é percebido por canções. Tudo o que o ser humano realiza faz parte da elaboração fenomenológica dos sons sob a vestimenta de um ritmo que se universaliza na medida em que se encontra individual, de forma natural, em todos os gestos desde o nascimento das criaturas até sua morte. 0 mundo é sentido por músicas. Desde o primeiro choro, todo indivíduo é atravessado por sentimentos e sensações que despertam diferentes formas e desejos de ouvir o mundo, ora com batidas aceleradas que circunscrevem a radicalidade do momento ou a angústia irrompida no silêncio, ora toques mais lentos que se complementam aos clichês amorosos ou a desilusões que trataram de congelar o corpo e as ideias. 0 sujeito passa mais tempo em uma antessala de um concerto do que propriamente experenciando a orquestra, isto é, absorve-se a música mais do que se produz canção de forma consciente. Como tudo é resultado de musicalidade, a expressão do sujeito se faz por meio de canções - até a fala cotidiana é construída com um ritmo muito evidente e, assim como uma música, dialoga com o outro. Ao partir de considerações de Emil Staiger, em Conceitos fundamentais da poética (1977), apresenta-se que

a música é esse remanescente, linguagem que se comunica sem palavras, mas que se expande também entoando-as. 0 próprio poeta confessa-o, quando compõe a canção (Lied) que destina ao canto. No canto, há uma elaboração da curva melódica, do ritmo. 0 conteúdo da frase passa a ter menor importância para o ouvinte. Acontece, às vezes, que o próprio cantor não sabe bem de que se fala no texto. (STAIGER, 1977, p. 8)
No que tange às experiências poéticas, Octavio Paz já observara que a poesia é a música do universo. No momento lírico, todas as energias do mundo batem sob o mesmo tambor, com as mesmas notas, realizando o mesmo ruído de quem compõe o poema. É uma mesma música que fornece uma espécie de artificialidade de momento. Artificial porque o tempo é fugaz e irrecuperável em sua plenitude. Por isso, quem lê, reativa essa canção de forma ilusória, e passa a vibrar em uma sintonia que se aproxima daquela do mesmo momento no qual ela foi composta. Ler um poema é, desse modo, participar de um ritual de recuperação e renovação de um nascimento primordial. Assim, o ato de um poema-canção é a evocação e também a concretização de um mito: é o próprio nascimento das possibilidades da vida, a conjuração de uma magia da boca de quem lê cada verso como quem constrói um universo do zero.

Ainda que muito da experiência musicalvital seja compartilhada, o fenômeno poético está muito voltado para a individualidade. Segundo Octavio Paz em Signos em rotação (1976), a poesia entra pelos olhos, o que a torna uma experiência (poética) solitária (PAZ, 1976, p. 117). Sob esta perspectiva, ao desintegrar o sentido auditivo, propício para a recepção da música, e reintegrá-lo ao caráter experencial do sentido da visão, próprio para a leitura, há uma conversão do fenômeno musical poético. Sabe-se que a musicalidade de um poema não é a mesma de uma canção tocada e cantada. Aquele, objeto desse trabalho, trata de uma construção linguística sintática, semântica e sonora que provém um novo espaço para a relação dialógica da linguagem. Sobre este aspecto pensa-se na palestra pronunciada na Universidade de Glasgow em 1942, intitulada "Musicalidade da poesia", por T. S. Elliot, na 
qual o autor diz que enquanto a poesia tenta exprimir algo além daquilo que pode ser expresso pela prosa, "ela permanece da mesma forma uma pessoa falando a outra; e isso é também verdadeiro na canção, pois cantar é outro modo de conversar" (ELLIOT, 1972, p. 50). Por esse motivo, passa-se a pensar a elaboração poética musical como uma conjunção de dois fatores: voz do sujeito poético e diálogo: o primeiro diz respeito a um eu-lírico que expressa sua percepção de si mesmo sobre o mundo em versos que cantam os sentimentos e pensamentos da vida; o segundo, uma proposta dialógica na qual, como será apresentado adiante, nem sempre o "tu" corresponde a uma pessoa distinta do "eu".

Conforme Octavio Paz, a poesia nasce no silêncio e no balbuciamento, no não poder dizer, "mas aspira irresistivelmente à recuperação da linguagem como uma realidade total. 0 poeta torna palavra tudo o que toca, sem excluir o silêncio e os brancos do texto" (PAZ, 1976, p. 120). Seguindo os ensinamentos de Paz, acredita-se que essa realização poética a partir do silêncio também se aproxime de uma composição musical, uma vez que o sujeito do poema declama versos - neste caso lidos no silêncio individual - em uma estrutura lírica versificada, ritmada e plurissignificativa.

Para elaborar a leitura dessas vozes líricas compositoras de canções-poemas, o presente estudo realizou uma seleção de quatro poemas presentes na obra Cantares de perda e predileção (1983), de Hilda Hilst, com o objetivo de apresentar diferentes nuances das expressões poemáticas levando em consideração o aspecto musical no arranjo das vozes dos sujeitos líricos e suas mensagens através dos versos. A despeito de não ser objetivo desta pesquisa aprofundar as aproximações e elucidar todos os fundamentos que diferenciam música e poesia, faz-se importante mencionar que poema e canção não estão tão distantes em seus fundamentos, embora trabalhem com a musicalidade de maneiras distintas e com diferentes instrumentos, e, por isso, pensar-se-á o poema como um parente da canção, sobretudo por acreditar que a obra de Hilst a ser estudada propicia a equiparação dos dois fenômenos artísticos desde a provocação em seu título até a concepção que circunscreve a obra: de que poesia é realizada pela música.

\section{Cantares de amor e de ódio: uma relação lírica}

Em Cantares de perda e predileção, Hilda Hilst convoca múltiplas vozes para confraternizarem em sua poética das paixões. Marcada e acentuada notavelmente na literatura do mundo moderno pelo menos desde Shakespeare, a paixão tem facilmente sido vinculada ao ódio, à inveja e a sentimentos que desestabilizam a razão. 0 amor e o ódio, em relação limítrofe, contrabandeiam as vozes na obra de Hilst de maneira a criar músicas que se disfarçam de solitárias quando, em muitos casos, estão a dançar em um salão cheio de outras vozes. Parece depender exclusivamente dos ouvidos e dos olhos que se voltam a esses poemas-canções para que, cedo ou tarde, quem os lê torne-se cúmplice dessas paixões que confabulam experiências singulares na literatura nacional.

Entre a realização da voz do poema e a musicalidade que todo o texto-discurso cotidiano apresenta, nota-se um prolongamento da poeticidade no que tange as relações amorosas. A paixão, usada muitas vezes como medida de tempo e de intensidade de outro sentimento, nos poemas de Hilst, apresenta a estruturação de um enunciado poemático carregado de intenções e expressões que encurtam a travessia casual: cada 
universo musical do poema aproxima-se da singularidade de cada paixão, sentimentofogo que não é apenas uma medida, conforme será observado nos poemas, também uma sensação própria do eu-lírico, com finalidade em si própria. Pode-se aproximar esta ideia de considerações de Staiger, ao dizer que

ao ouvirmos música, a distância ou proximidade só influem até certo ponto, porque os instrumentos a uma certa distância soam melhor. A distância ideal do instrumento é comparável à propícia iluminação dos quadros. A distância, todavia, não cria um frente a frente objetivo como no caso do quadro que nos é "exposto" e que podemos, quando ele não está presente, imaginar. Sobre a música são válidas as palavras de Paul Valéry que dizem: a música suprime o espaço. Estamos nela e ela em nós. (STAIGER, 1977, p. 25)

Visto que cada poema compõe seu próprio universo significativo e musical, olharse-á para cada texto selecionado como quem encara, pela primeira vez, uma possibilidade da vida. Como os poemas não possuem títulos, eles serão apresentados seguindo a numeração adotada dentro da obra. Vejamos como o poema-canção discorre acerca dos sentimentos do eu-lírico no primeiro caso:

\section{I}

Vida da minha alma:

Recaminhei casas e paisagens

Buscando-me a mim, minha tua cara.

Recaminhei os escombros da tarde

Folhas enegrecidas, gomos, cascas

Papéis de terra e tinta sob as árvores

Nichos onde nos confessamos, praças.

Revi os cães. Não os mesmos. Outros

De igual destino, loucos, tristes,

Nós dois, meu ódio-amor, atravessando

Cinzas e paredões, o percurso da vida.
Busquei a luz e o amor. Humana, atenta Como quem busca a boca nos confins da sede. Recaminhei as nossas construções, tijolos Pás, a areia dos dias.

E tudo que encontrei te digo agora:

Um outro alguém sem cara. Tosco. Cego.

0 arquiteto dessas armadilhas.

(pág. 354) ${ }^{1}$

0 texto que abre o volume de poemas é estruturado em quatro estrofes. Nele, é possível perceber a construção da voz poemática a partir de elementos que percorrem dois caminhos: por um lado, sintagmas concretos que remetem a espaço físico, mais especificamente, do solo, do pátio, da terra; por outro, há um movimento de alteridade que propicia o (re)conhecimento do eu-lírico através do movimento: trata-se de um caminhar constante, uma jornada, uma aventura. Ao elaborar a percepção de mundo sob o viés do outro, o sujeito poético fala de si na perspectiva de uma relação a dois. Assim, ao falar dos caminhos que percorreu, dos objetos que viu e das buscas que realizou, o sujeito do poema fala de si, de seu modo de sentir a vida e as coisas e, sobretudo, de seus sentimentos em relação a um ser amado.

0 primeiro verso da primeira estrofe é de suma importância para a leitura aqui proposta: o verso "vida da minha alma" sucedido por dois pontos introduz um espaço para elencar ações desenvolvidas pelo "eu" que explicam seus objetivos e suas sensações: elabora-se uma jornada na qual as casas e as paisagens são atravessadas em busca de uma expressão do "outro" que, em última instância, revela a expressão de si ("buscando-me a mim, minha tua cara"). Nota-se que buscar a si significa para este sujeito poéti-

1 Todos os poemas citados e transcritos ao longo deste trabalho estão presentes na mesma edição: Hilda hilst: da poesia (2017), da editora Companhia das Letras. 
co buscar o outro, porque no panorama da relação, os dois convergem em um mesmo ser. Amar o outro é possivelmente amar-se. No quarto verso do poema, ao referenciar os "escombros da tarde", o eu-lírico indica para uma instância do passado com nostalgia: são recordações e experiências vividas que não se mantiveram plenamente erguidas são escombros. A tarde é um elemento significativo para evocar um cenário meditativo e mediano: nem é manhã, signo de nascimento, nem noite, símbolo do fim. Além destes elementos, outros são os sintagmas que apontam para a deterioração dos valores vividos: folhas "enegrecidas", "papéis de terra" e mesmo "tinta sob as árvores", todas presentes ainda na primeira estrofe e permeados pela ideia de algo temporário, que há de sumir. Há ainda, nessa primeira parte (se permitirmos olhar para uma estrofe como uma porção de um todo significativo), o verbo confessar apresentado na primeira pessoa do singular, que aproxima novamente o outro do eu e revela a tendência para um amor proibido, problemático ou secreto. A confissão geralmente carrega em si um sentido de segredo e/ou culpa: confessamos aquilo que ocultávamos.

Pode-se, desse modo, ressaltar as palavras de Emil Staiger, com a finalidade de analisar a "imprecisão" do estado lírico quanto à funcionalidade da língua, isto é, seu uso de modo particular, ao dizer que

a unidade e coesão do clima lírico é de suma importância num poema, pois o contexto lógico, que sempre esperamos de uma manifestação linguística, quase nunca é elaborado em tais casos, ou o é apenas imprecisamente. A linguagem lírica parece desprezar as conquistas de um progresso lento em direção à clareza, - da construção paratática à hipotética, de advérbios a conjunções, de conjunções temporais a causais. (STAIGER, 1977, p. 17)
A partir dessa perspectiva, destaca-se o papel da passionalidade na constituição dos versos e do discurso lírico apresentado até aqui. Não se faz necessário elaborar um texto que obedeça a uma manifestação diferente do conteúdo da reflexão de si mesmo que é, em última instância, o laboratório de enunciação poética. Com isso, entende-se que a incerteza entre um outro ou o si mesmo como endereçado do discurso poético observado é justificado pelo tipo de manifestação da experiência lírica, que secundariza uma lógica linguística dialógica para enfatizar o conteúdo como uma fenomenologia do eu.

Ao chegar na segunda estrofe do poema, a relação antitética entre amor e ódio é explicitada através da percepção dos sentidos humanos que não apenas observam com distância tais sentimentos, mas também os sentem. Os cães vistos de novo pelo sujeito poético (e aqui é importante destacar a recorrência da ação, assim como na primeira estrofe: trata-se de um acontecimento repetido, não inédito: recaminhei, revi) são outros. Se antes eles guardavam a lealdade do amor, a complexidade do afeto sincero e devotado, agora resguardam um semblante triste e louco. É verdade que carregam o mesmo destino de outrora, mas já não são os mesmos, o que revela a possibilidade da mudança de sentimentos. A personificação das subjetividades é explicitada no terceiro e no quarto verso dessa estrofe: "nós dois, meu ódio-amor, atravessando / cinzas e paredões, o percurso da vida". A riqueza destes versos está na ambiguidade da ressignificação da oração. "Meu ódio-amor" funciona tanto como um vocativo para o eu-lírico com quem ele fala, quanto como explicação de "nós dois": nós dois, isto é, meu amor e meu ódio. Sob esta perspectiva, o sujeito poético assume a face de dois sentimentos 
simultâneos, despersonalizando-se. Vale destacar ainda nesta estrofe uma característica semântica que aproxima a construção discursiva de uma canção (um fado?) que murmura os lamentos de uma voz opaca. Essa característica, tão cara a Hilst quanto a este estudo, aproxima-se da ideia de desejo observada por Octavio Paz:

por obra da imaginação o homem sacia o seu infinito desejo e converte-se ele mesmo em um ser infinito. 0 homem é uma imagem na qual ele mesmo se encarna. 0 êxtase amoroso é essa encarnação do homem em sua imagem: uno com o objeto de seu desejo, uno consigo mesmo. (PAZ, 1976, p. 80)

Na terceira estrofe do poema, o sujeito poético revela dois elementos novos: primeiro, marcas de gênero feminino ${ }^{2}$; segundo, a consciência de sua busca por amor e luz, elementos geralmente revestidos de positividade, através da paixão carnal, isto é, no outro. Buscar a boca, ou seja, o beijo, remete a uma busca por significação profunda nas relações humanas. Trata-se de crer no poder dos laços físicos como cura para os sofrimentos sentimentais e, por que não, psíquicos. 0 eu-lírico assume, assim, uma nova canção: com otimismo, o caminho novamente percorrido agora assimila as construções, desde sua base em tijolos e areia, da relação dos indivíduos. Não há espaço mais para folhas mortas e tempo obscuro. Os dias são finos como areia, e o tempo dilui-se dessa forma, escorrendo pela mão exatamente como deveria ser.

2 Este ponto é de suma importância e parece recorrente no conjunto poético de Hilst. Entretanto, por não ser objeto devidamente tratado neste trabalho, não se pretende entrar nesta seara, que seria superficialmente tratada. Recomenda-se pesquisa e análise mais ampla da obra poética de Hilda Hilst sobre este aspecto, ficando assim como sugestão para pesquisadores interessados ou como dívida a ser recuperada futuramente em outro trabalho.
Ao chegar na estrofe conclusiva do texto, o eu-lírico explicita o diálogo com o outro para a realização de resumo confessional do resultado de sua jornada: assim como os cães revistos, esse alguém revisitado também já não é o mesmo, não possui a mesma face, nem o olhar, que agora é como "cego". Destituem-se os elementos reconhecíveis de outrora porque assim como as pessoas (ou os cães), o amor muda e já não é mais o que era necessário ser. Embora tenha incorrido de um lampejo de otimismo, o sujeito poético percebe que a transformação é um elemento natural da vida e que as características que em outro tempo pareceram essenciais soam agora apenas como uma armadilha de suas lembranças. E neste novo cenário, o outro é apenas um arquiteto com um projeto desacreditado. De forma distinta acontece no poema a seguir, no qual os sentimentos apresentados sob a máscara de um pronome da primeira pessoa do plural oculta desejos íntimos:

\section{XI}

Faremos deste modo

Para que as mãos não cometam

Os atos derradeiros:

Envolveremos as facas e os espelhos

Nas lãs dobradas, grossas.

E de alongadas nódoas, o ressentimento.

Pintadas as caras num matiz de gesso

Recobriremos corpo, carne

Na tentativa cálida, multiforme

Na rubra pastosidade

De um toque sem sofrimento.

E afinal

Cara a cara (espelho e faca)

De nossas duplas fomes

Não diremos.

(pág. 361) 
O poema transcrito apresenta uma forma sonora com ritmo marcado por assonâncias que provocam subidas e descidas de tom mas sempre localizadas na região mediana/ baixa das vogais. Essa alternação simula uma dança entre os versos, como uma valsa que troca de um lado para o outro do salão do poema. Assim é a paixão retratada neste texto: um combate ensaiado sob uma canção ritmicamente delineada por uma voz poética complacente.

Na primeira estrofe do poema, apresenta-se o verbo fazer sob a forma da primeira pessoa do singular (novamente esta característica em seus poemas), que oculta o pronome "nós". Trata-se, assim, de uma voz poética que acolhe o outro em suas ações e percepções. Nesta estrofe, ocorre uma apresentação de um modo de agir que deve ser seguido para o bom de ambos os indivíduos. A ação perturbada e proibida pode ocorrer através das mãos. Elas são as responsáveis pelos possíveis "atos derradeiros". Pode-se pensar a partir daí a função do corpo como traidor das emoções, uma vez guiados por impulsos que dizem respeito ao subconsciente. A voz que fala no poema também apresenta a postura dominante, sendo ela quem dá as diretrizes do que deve ser feito em prol de um bem que parece de comum acordo aos dois sujeitos.

$\mathrm{Na}$ segunda estrofe, novamente o início do verso apresenta a elipse do pronome "nós" sob a forma do verbo na primeira pessoa do plural do verbo "envolver". Dois elementos protagonizam a estrofe: por um lado, as facas, que apresentam, em última instância a tendência à reação-limite do corpo humano de pender para a violência e o gesto brutal; por outro lado, os espelhos, que revelam o medo e a necessidade de encarar a própria face em busca de conhecimento e salvação - ou seria a concretização da per- dição? É interessante notar como ambos objetos, facas e espelhos, serão envolvidos por lãs grossas dobradas, que irão resguardar os temores e a impulsividade. No entanto, o sujeito poético informa: trata-se de ressentimento, que funciona como uma armadura que veste a falsa sensação de proteção.

A ideia de evitar o mal através da cobertura do corpo é melhor desenvolvida na terceira estrofe do poema. Nesta estrofe, os rostos são pintados, o corpo coberto e, assim, busca-se apagar o fogo ignorando-o. Entretanto, conforme é possível observar na quarta estrofe, isolada em si por um verso solitário, e complemento da estrofe anterior, a tentativa almeja disfarçar o sofrimento. Como o palhaço que maquia o rosto e provoca risos mesmo que internamente esteja infeliz, o eu-lírico empreende uma retomada da relação a dois através da desconsideração dos males pré-existentes.

Não é à toa que o desfecho do poema, presente na quinta estrofe, possui o sintagma fome ("duplas fomes") como representante dos desejos reprimidos pelos sujeitos do poema. Somente no momento decisivo, cara a cara - e então retomando a face e o espelho - é que o sujeito poético admite a necessidade de algo a mais, algo inalcançável e por isso, silenciado. 0 silêncio derradeiro é encontrado no último verso, introduzido sob a forma de uma cisão semântica "não diremos", sem que se saiba, jamais, o que não será dito. Por não configurar uma realidade concreta e totalmente preenchida, apenas esboços de possibilidades, o poema condiz com a reflexão acerca de sentimentos e sensações fugazes. Até mesmo o silêncio que parece se eternizar no poema tende a ser interrompido por uma voz que, em algum momento, há de nascer. Sobre esse fenômeno pode-se recuperar Staiger, ao dizer que 
para o poeta lírico não existe uma substância, mas apenas acidentes, nada que perdure, apenas coisas passageiras. Para ele, uma mulher não tem "corpo", nada resistente, nada de contornos. Tem talvez um brilho nos olhos e seios que o confundem, mas não tem um busto no sentido de uma forma plástica e nenhuma fisionomia marcante. Uma paisagem tem cores, luzes, aromas, mas nem chão, nem terra como base. Quando falamos na poesia lírica, por essa razão, em imagens, não podemos lembrar absolutamente de pinturas, mas no máximo de visões que surgem e se desfazem novamente, despreocupadas com as relações de espaço e tempo. (STAIGER, 1977, p. 21)

Conforme comentado inicialmente, o poema também sustenta a forma de uma canção: apresenta, na primeira estrofe, a introdução da problemática para, nas estrofes seguintes mostrar as alternativas e efeitos e, na última parte, concluir a ideia. É uma canção que segue a estrutura da música popular em forma de balada, uma narrativa romântica com específicos pontos focais sonoros que salientam determinados sintagmas. A começar na primeira estrofe e seguir até a última, a vogal /o/ é apresentada como subvogal singular e plural da vogal predominante "e" (“derradeiros", “envolveremos”, "espelhos", "ressentimento", "gesso", "recobriremos", "sofrimento", “diremos"); Também aparece a vogal /o/ e /ó/ como protagonista da palavra nos casos "modo", "nódoas", “corpo", "multiforme", "toque" e "fomes". Com essas informações, aponta-se para a tendência de textos com destaques para vogais fechadas em "o" de tratar de assuntos pesados, obscuros e problemáticos. As canções, por sua vez, também tendem a tratar de assuntos mais alegres e positivos quando permeadas por vogais abertas (como /a/ e /é/). As marcas de plural ("faremos", "mãos", "atos", "derradeiros", "espelho" etc) auxiliam na marcação temporal da leitura, seguindo um método típico da canção, que utiliza, dentre outros métodos, da repetição como forma de criação de intimidade entre o público e a estrutura artística. Ao assumir um caráter ainda mais individualista, o poema a seguir parece compor uma canção de súplica que transborda os limites entre amor e ódio:

\section{XXIX}

Faz de mim tua presa:

Raiz para o teu ódio

Amor para o meu navegar

E abrandado cessa

De lançar tua rede

Tua armadilha.

Faz de mim tua sombra

E injuria, sangra

Essa que te descansa

Na tua soberba escalada ao meio-dia.

Golpeia

Para amansar tua fina presa.

Faz de mim tua boca

E cobre de saliva

Tua cria de carne e solidão.

E abrandado cessa

Teu exercício de virtude e treva.

(pág. 373-374)

No poema transcrito fica evidenciada a visão do eu-lírico a respeito do amor: uma batalha entre ódio e paixão, uma caça. A relação limítrofe da paixão, pendendo ora para um lado bom, ora para um lado ruim é a grande chaga notada neste poema. A expressão do sujeito poético é dividida em três estrofes que partilham de diferentes momentos do desejo erótico e psíquico de se viver um estado de tensão que o amor possibilita. 0 poema-canção apresenta um eu-lírico em diálogo constante e explícito com o outro, ser desejado e também desejante. 
Logo na primeira estrofe do poema fica evidente a intenção do eu-lírico: ser objeto de paixão-desejo pelo outro. Só que esse desejo, sabe-se, facilmente flerta entre paixão e ódio, pois ambos são estados de alma evocados de um mesmo ponto: a erupção de sentimentos e sensações que ardem e inflamam. Ser caçada pelo desejado representa para este sujeito poético originar a ira e também a calmaria de um mar; a caça participa de um jogo do amor no qual é preciso ser domada para que se alcance o êxtase do prazer. A relação, assim, amor-ódio é inundada de erotismo. A auto-objetificação promove a sensualidade, mas também uma percepção de consciência corporal e emocional: deixar-se ser pega demonstra a confiança de que não é preciso estar no topo para saber seu valor. Conforme bem salienta o eu-lírico no sexto verso da primeira estrofe, o amor é uma armadilha: alguém sempre vence. É este modo de ver o mundo e as relações humanas que condiciona o desejo, que parte sempre de uma ausência. Ausentar-se da vida do outro é promover nele o desejo de reaver o que perdeu. 0 claro endereçamento do poema a um outro, no entanto, não facilita a situação: não há garantias de que algo seja (cor)respondido, visto que no poema só há espaço para a voz do eu-lírico, que é capaz de pensar e de sentir pelo outro, traduzindo assim seus próprios desejos e suas aflições sob a forma de vazios ou de palavras que talvez nunca existam a partir de outra boca. Lembra-se, assim, de Staiger, ao se referir a canções de amor e nas relações entre a voz poética e sua musa, dizendo que "um você lírico só é possível quando amada e poeta formam "um coração e uma alma". O lamento do amor não correspondido diz um "você", que o eu sabe não terá eco" (STAIGER, 1977, p. 23).
Na segunda estrofe do poema explicitase o desejo carnal de tornar-se vulnerável e submissa à paixão. 0 corpo torna-se sombra do outro, na promulgação do sexo, o sangue, material de univocidade do ser permite-se como tinta para colorir a calmaria da fúria amorosa. Ler o poema é reescrever a paixão e o desejo. Permitir-se segredar a voz que busca o amor é tornar-se cúmplice do ódio. Ao revelar-se fraca e "fina presa", o eu-lírico brinca com o fetiche da dominação - seria o ódio dominando o amor ou o amor dominando o desejo? De acordo com Octavio Paz, a poesia apresenta uma relação de contradições na qual separação e união compõem uma exegese lírica que condiciona as ambiguidades observadas e sentidas por cada sujeito poético. Ainda segundo o autor,

o crescimento do eu ameaça a linguagem em sua dupla função: como diálogo e como monólogo. 0 primeiro se fundamenta na pluralidade; o segundo, na identidade. A contradição do diálogo consiste em que cada um fala consigo mesmo ao falar com os outros; a do monólogo em que nunca sou eu, mas outro, o que escuta o que digo a mim mesmo. A poesia sempre foi uma tentativa de resolver esta discórdia através de uma conversão dos termos: o eu do diálogo no tu do monólogo. A poesia não diz: eu sou tu; diz: meu eu és tu. A imagem poética é a outridade. (PAZ, 1976, p. 102)

Exercitar o amor é percorrer o caminho da escuridão: como é possível proteger algo tão puro sem lidar com o mal? Essa pergunta é desencadeada da reflexão presente na terceira estrofe do poema: o "exercício de virtude e treva" retém em si a chave para desvelar os segredos do amor -ódio: em que medida um torna-se o outro? Há equilíbrio entre eles? Um precisa cessar para que o outro aja? Tornar-se a boca do outro é transportar-se para sua voz. Assim, essa união de palavras é também uma jun- 
ção de carne e espírito - é, em última instância, a invasão na solidão. Desabita-se o próprio corpo para invadir o corpo estranho e desejado. A carne é uma vestimenta para o sujeito poético, uma veste descartável em prol da união dos corpos. Cantar essa canção é cantar o ódio de precisar do amor para se tornar mais humano. Já no quarto poema a ser destacado, essa sensação é balizada por uma amenização que tende a inclinar o indivíduo a questionarse e a considerar o amor de forma menos radical e até mesmo mais otimista:

\section{XLI}

Ouvia:

Que não podia odiar

E nem temer

Porque tu eras eu.

E como seria

Odiar a mim mesma

E a mim mesma temer

Se eu caminhava, vivia

Colada a quem sou

E ao mesmo tempo ser

Dessa de mim, inimiga?

Que não podia te amar

Tão mais do que pretendia.

Pois como seria ser

Pessoas além do que me cabia?

Que pretensões de um sentir

Tão excedente, tão novo

São questões para o divino

E ao mesmo tempo um estorvo

Pra quem nasceu pequenino.

Tu e eu. Humanos. Limite mínimo.

(pág. 382-383)

No poema transcrito, a relação entre amor e ódio parte de uma relação de alteridade entre o eu-lírico e o outro: odiá-lo sig- nificaria odiar a si mesmo. Mas este conceito não partiu do próprio sujeito poético. Foi algo ouvido. Seria esta uma lição compreensiva do ponto de vista do desejo de amor? De acordo com o que é apresentado na primeira estrofe do poema, odiar e temer são dois verbos que devem ser evitados, pois o efeito de ação e reação ocorreria de forma imediata. Embora pareçam questões superficialmente elaboradas, há uma singeleza na maneira como as perguntas - e as respostas - se formam: ao questionar a respeito de temer a si próprio, o sujeito poético reflete sobre a impossibilidade de descolar-se de si e tornar-se inimigo do próprio eu. Esta parece uma forma sutil e metafórica de apresentar uma questão cara à modernidade: o narcisismo. Mas vai além: manter as pazes consigo próprio é, em última instância, uma maneira segura de permanecer e resistir. Caminhar colado aos seus próprios ideias e a sua maneira de ser é um ato político e social. Essa questão pode ser atrelada à percepção de Staiger sobre a poesia e sua utilidade - que, de modo geral, diz respeito à canção:

as canções não se fazem necessárias. Não resolvem problemas. Não podemos recorrer a elas. Quem gostaria de tomar, uma vez que fosse, um perfume, algo flutuante ou atmosférico, como testemunha de qualquer coisa? Uma canção pode consolar-nos, mas não nos pode ajudar. É antes uma amada que um amigo em quem nos apoiamos para lançarmo-nos à obra ou à ação, e antes uma amada que uma esposa, que está ligada para sempre ao marido. Tudo isso leva à conclusão de que a poesia lírica nada domina, não tem objeto em que incidir qualquer espécie de força, e que, enfim, é cheia de alma mas não tem espírito. (STAIGER, 1977, p. 37)

Assim como as canções, que não têm utilidade, mas que servem para algo, o eu-lírico ouvia que não podia amar mais do que 
pretendia, como se fosse possível medir o amor em quantidades e ações. 0 quanto se pretende envolver-se com o outro? Quanto se almeja entregar? Quanto se busca desejar? Se estas questões não podem ser plenamente respondidas, elas provocam uma reflexão mais profunda: há uma medida em que se torna impossível amar a si mesmo e ao outro concomitantemente? Se canções não resolvem problemas, por que criar poemas-canções que convocam um amor doloroso? 0 amor-ódio torna-se amor-receio e esse temor de ser grande demais para caber em si mesmo poderia propiciar uma longa discussão psicanalítica. Contudo, como este não é o foco pretendido, tampouco se levanta um aparato teórico para tal, desviemos a discussão para outra ótica: qual é o poder da influência externa (isto é, de outros) sobre o ato de amar e sobre a criação das cançõespoemas?

O sujeito poético surge com uma nova camada que se não responde a questão anterior, no mínimo provoca tendências de respostas: a pequenez humana frente ao divino. Pode-se discorrer acerca das representações do divino compreendido pela poética de Hilda Hilst. Tomemos como ponto central, ao partir do poema transcrito, o amor como o divino utópico. Toma-se este prisma de leitura porque há a delineação de um sentimento de diminuição da condição humana em relação a algo maior e infinito. "Tu e eu. Humanos. Limite mínimo". 0 amor, ou melhor, a ideia de vontade de amor que existe entre dois sujeitos parece pequena se comparada ao sentimento em si. A ação dinâmica de colocar o amor em perspectiva direta torna-o consciente e, por conseguinte, humano. Retoma-se, assim, a ideia dos cantares, que originam o título da obra: não seriam todas as canções humanas sobre amor e sobre amar?

\section{Sobre musicalidade:}

\section{sentimentos-limites, paixão e o que mais?}

No poema "Destruição", presente na obra Lição das coisas (1962), o eu-lírico de Carlos Drummond de Andrade diz que "os amantes se amam cruelmente / e com se amarem tanto não se veem. / Um se beija no outro, refletido. / Dois amantes que são? Dois inimigos". As ambiguidades da paixão apresentadas ao longo do soneto italiano de Drummond conversam com as perspectivas duais dos poemas aqui apresentados de Hilda Hilst: a paixão funciona como uma espécie de força capaz de sobrepujar a consciência de si mesmo ao passo que transita por um território de crueldade. A crueza dos sentimentos humanos é realçada pela perspicácia de eus-líricos que entoam canções da grande pequenez humana. A potência sinestésica, por este motivo, amplia os possíveis sentidos humanos, ao passo que também os desorienta: cheiro, gosto, toque, imagem burlam uns aos outros de maneira que ressignificam a estética poética, assim como apaixonados encontram novos sentidos no aparentemente banal.

Sob o funcionamento desses jogos nem sempre lógicos, os sujeitos poéticos concebem canções como quem escreve em diários o cotidiano: uma rotina mística de encontros e desencontros que multiplicam as formas de sentir. Sentir, aliás, parece o verbo-chave para tratar desse recorte da poética de Hilst. É preciso reconhecer o apelo por uma sensibilidade corpórea e psíquica para adentrar nos versos que se apresentam. Se de acordo com Octavio Paz "o poema acolhe o grito, os trapos vocabulares, a palavra gangrenada, o murmúrio, o ruído e o sem-sentido: não a in-significância" (PAZ, 1976, p. 120), para ser ainda mais específico, estes poemas de 
Hilst tratam de retalhos de sensações que, uma vez remendados, revivem os sentimentos da paixão. Apaixonar-se diz respeito a uma queda profunda a uma condição insólita: cai-se por alguém como quem sonha que perde as asas em meio ao voo.

Em meio a paixão, a canção surge como metáfora e método: aquela, por ser uma maneira de constituir o discurso de maneira simbólica entre amantes, mas também por representar uma ilusão da paixão como caminho para a auto-aprendizagem - o aprender de si mesmo, pouco a pouco, como tudo nesses poemas de Hilst, de maneira comedida, embora intensa; este, como ética de uma poesia comprometida com contracenar possibilidades de tornar plausível a paixão que não se mede e não se racionaliza. Porque, em suma, faz parte do roteiro e do processo de apaixonar-se deixar de ser um pouco de si mesmo para tornar-se parte do outro. Dessa forma, também o outro deve dançar sob a mesma canção para integrar, gradualmente, pouco de si.

Tratar aqui de poema-canção não diz respeito a interpretar todo o discurso histórico da arte que percebe o ritmo como elemento que vincula as duas expressões, tampouco objetiva apreender as relações naturais entre os primeiros poemas cantados e a música que se faz espetáculo na contemporaneidade. Ao mesmo tempo, contudo, é um fenômeno que percebe estes dois movimentos e muitos outros. Nas palavras de T. S. Elliot, afinal de contas, "a musicalidade do verso não está em cada linha, mas no poema como um todo" (ELLIOT, 1972, p. 57), e por pensar o poema como um todo, pensa-se na canção que ele traduz: no caso aqui relatado de Hilst, canções que anunciam e relatam paixões. Dessa forma, cantar a ausência e o desejo ou, nas palavras da poeta, as perdas e as predileções, é evocar a alma de quem se apaixona, de quem suplica, de quem sofre, de quem se entrega e de quem almeja ser tomado... paulatinamente até perder si mesmo e tornar-se, quem sabe, pouco mais de um novo eu.

\section{Referências}

ELLIOT, Thomas Stearns. A essência da poesia. Introdução de Affonso Romano de Sant'anna. Tradução de Maria Luiza Nogueira. Rio de Janeiro: Artenova, 1972.

HILST, Hilda. Cantares de perda e predileção. In: Hilda Hilst: Da Poesia. São Paulo: Companhia das letras, 2017.

PAZ, Octavio. Signos em rotação. São Paulo: Perspectiva, 1976.

STAIGER, Emil. Conceitos fundamentais da poética. Trad. Celeste Aída Galeão. Rio de Janeiro: Tempo Brasileiro, 1977.

Recebido em: 15/03/2021 Aprovado em: 07/08/2021 